\title{
Assessment of quality of life in individuals with chronic headache. Psychometric properties of the WHOQOL-BREF
}

\author{
Patrick Brzoska@
}

\begin{abstract}
Background: The WHOQOL-BREF is a frequently used instrument for the assessment of health-related quality of life. Unlike other generic instruments used for the assessment of this construct, little is known about its properties in individuals with headache disorders. The present study examines the reliability and factorial validity of the WHOQOL-BREF in individuals with chronic headache residing in Austria.

Methods: Data from a representative population-based survey on 963 individuals with chronic headache surveyed between 2013 and 2015 was used. The factorial validity was examined by means of confirmatory factor analysis. Differential item functioning related to sex was analyzed using multiple indicators multiple causes models.

Results: Information on 239 men and 724 women with chronic headache was available. The four-factor, 24-item baseline model showed a moderate fit (RMSEA $=0.066 ; \mathrm{CFI}=0.868 ; \mathrm{TLI}=0.852 ; \mathrm{SRMR}=0.053)$, which improved significantly after the addition of six error covariances (RMSEA $=0.052 ; \mathrm{CFI}=0.920$; $\mathrm{TLI}=0.908$; $\mathrm{SRMR}=0.046$ ). Sexrelated differential item functioning was observed in two items of the environment factor, two items of the psychological health factor and two items of the physical health factor.

Conclusions: After some modifications to the measurement model, the WHOQOL-BREF shows a satisfactory fit among individuals with chronic headache in Austria. Because of these modifications and the questionnaire's susceptibility for differential item functioning, a latent variable framework should be employed for the analysis. Future studies need to confirm these results for other language regions and should also examine different subtypes of headache.
\end{abstract}

Keywords: Quality of life, Assessment, Differential item functioning, WHOQOL-BREF

\section{Background}

Health-related quality of life (HRQOL) is an important patient-reported outcome in health research and practice. It is used as an indicator in clinical trials, in the evaluation of health care services and for benchmarking purposes. Differences in HRQOL between population groups can help to identify deficits in health care and to guide measures aiming to reduce disparities [1]. Also for

Correspondence: patrick.brzoska@uni-wh.de

Health Services Research, Faculty of Health, School of Medicine, Witten/

Herdecke University, Alfred-Herrhausen-Straße 50, D-58448 Witten, Germany headache disorders the measurement of HRQOL is necessary to assess how headaches affect individuals in their daily activities and to evaluate the effectiveness of therapeutic regimens, thus being indispensable to ensure patient-centered health care. In previous studies, for example, HRQOL has been used as an outcome to study the effectiveness of pharmaceutical [2] and psychological interventions [3] in patients with migraine or to examine how headache disorders are related to well-being in different population groups [4].

(c) The Author(s). 2020 Open Access This article is licensed under a Creative Commons Attribution 4.0 International License, which permits use, sharing, adaptation, distribution and reproduction in any medium or format, as long as you give appropriate credit to the original author(s) and the source, provide a link to the Creative Commons licence, and indicate if changes were made. The images or other third party material in this article are included in the article's Creative Commons licence, unless indicated otherwise in a credit line to the material. If material is not included in the article's Creative Commons licence and your intended use is not permitted by statutory regulation or exceeds the permitted use, you will need to obtain permission directly from the copyright holder. To view a copy of this licence, visit http://creativecommons.org/licenses/by/4.0/ The Creative Commons Public Domain Dedication waiver (http://creativecommons.org/publicdomain/zero/1.0/) applies to the data made available in this article, unless otherwise stated in a credit line to the data. 
An important requirement for the use of HRQOL as an indicator in research and practice is the valid and reliable assessment of this construct. Comparable to other psychological constructs, HRQOL is usually assessed by means of multi-item self- or interviewer-administered questionnaires where different latent dimensions ('factors') are measured by a set of observable items ('indicators') [5]. Despite focusing on quality of life in general, the short version of the World Health Organization Quality of Life (WHOQOL) questionnaire (WHOQOL$\mathrm{BREF}$ ) is one of the most frequently used generic instruments applied for this purpose [6]. Based on the 100item WHOQOL [7], the WHOQOL-BREF consists of 24 Likert scale items on different facets of HRQOL (such as pain, sleep, self-esteem and sexual activity) which represent four latent HRQOL dimensions: physical health, psychological health, social relationships and environment. Two additional items, which are not part of the aforementioned measurement model, assess individuals' satisfaction with life and their overall quality of life. The WHOQOL-BREF uses a 5-point Likert response format with six sets of response categories (e.g., 1 "Not at all" to 5 "completely" or 1 "Very dissatisfied" to 5 "Very satisfied"; see Table 2 for response categories by items). With the exception of three inversely coded items, a higher score on each item indicates a higher quality of life with respect to the facet the item is measuring. In substantive research, the WHOQOL-BREF is either examined based on the four aforementioned dimensions (e.g., [8-11]) or these dimensions are summarized into a global quality of life score, effectively extending the four-factor measurement model into a second-order model (e.g., [1215]).

The WHOQOL-BREF has been frequently used to examine the HRQOL of patients with different chronic conditions, including headache disorders [16-19]. Although previous studies have shown that the WHOQOL-BREF can be applied across different diagnostic groups [20], some studies have indicated that modifications to the measurement model of the WHOQOL-BREF may be necessary to achieve sufficient model fit [21-23]. Research has also indicated that some items may be prone to differential item functioning related to sociodemographic variables such as age and sex [24-26]. Differential item functioning refers to the situation in which items perform differently across population groups despite the underlying dimensions these items are purported to measure are held constant. This for example means that men and women with the same level of HRQOL may a have different probability for a certain item response [27].

Whereas the performance and psychometric properties of other generic HRQOL assessment instruments such as the SF-36 and the EQ-5D have been examined among individuals with headache disorders [28], little is known about the validity of the WHOQOL-BREF in this respect. Confirming the validity of the WHOQOL-BREF in individuals with headache disorders could further promote the use of quality of life as a quality indicator in headache care [29, 30]. Extending own previous research on the subject [31], the aim of the present study was to examine the reliability and factorial validity of the WHOQOL-BREF in a representative population-based sample of individuals with self-reported chronic headache residing in Austria and to assess its measurement equivalence between men and women.

\section{Methods}

\section{Data and variables}

Data from a representative cross-sectional populationbased health survey conducted in Austria between 2013 and 2015 ('Austrian Health Interview Survey 2014') was used providing information on 963 respondents with self-reported chronic headache. The German-language anonymous and voluntary survey was carried out by the Austrian statistical office ('Statistics Austria') by means of computer-assisted telephone interviewing. Its implementation is part of the health reporting activities which Statistics Austria is routinely conducting and fulfils all requirements and guidelines of the Federal Statistics Act. Survey participants provided informed consent prior to their participation. Researchers can obtain the data used in the present study free of charge from Statistics Austria [32].

Aside from the 24 items of the WHOQOL-BREF, information on age (15-29 years, 30-44 years, 45-59 years, $60+$ years), sex, partnership status (living in a partnership, not living in a partnership), educational level (primary/lower secondary, upper secondary/post-secondary [non-tertiary], tertiary education [bachlor, master, doctoral]) and net equivalence income (quantiles) were used for purposes of sample description in the present study. Respondents' education was measured by means of eight categories following the International Standard Classification of Education (ISCED) [33].

\section{Statistical analysis}

$\chi^{2}$-tests were calculated for purposes of sample description (Table 1). For each of the 24 items of the WHOQOL-BREF measurement model also means, standard deviations (sd), skewness and kurtosis have been calculated, and the distribution of the items has been examined graphically be means of histograms. In addition to skewness and kurtosis, also the results of omnibus normality tests based on these two measures are reported [34]. Multivariate normality has been examined by means of the Henze-Zirkler test [35]. A 
Table 1 Description of the study sample by sex (individuals with self-reported chronic headache residing in Austria, Austrian Health Interview Survey, 2013-2015, $n=963$ )

\begin{tabular}{|c|c|c|c|}
\hline & \multicolumn{2}{|l|}{ Sex } & \multirow{2}{*}{$\begin{array}{l}p- \\
\text { value* }\end{array}$} \\
\hline & Male & Female & \\
\hline $\mathbf{N}$ & 239 & 724 & \\
\hline Age & & & 0.22 \\
\hline $15-29$ years & $28(11.7 \%)$ & $84(11.6 \%)$ & \\
\hline $30-44$ years & $72(30.1 \%)$ & $263(36.3 \%)$ & \\
\hline $45-59$ years & $91(38.1 \%)$ & $265(36.6 \%)$ & \\
\hline $60+$ years & $48(20.1 \%)$ & $112(15.5 \%)$ & \\
\hline Partnership status & & & 0.80 \\
\hline Living in a partnership & $150(62.8 \%)$ & $461(63.7 \%)$ & \\
\hline Not living in a partnership & $89(37.2 \%)$ & $263(36.3 \%)$ & \\
\hline Net equivalence income of respondent's household & & & 0.34 \\
\hline Below 1st quantile & $64(26.8 \%)$ & $183(25.3 \%)$ & \\
\hline Between 1st and 2nd quantile & $48(20.1 \%)$ & $177(24.4 \%)$ & \\
\hline Between 2nd and 3rd quantile & $41(17.2 \%)$ & $146(20.2 \%)$ & \\
\hline Between 3rd and 4th quantile & $49(20.5 \%)$ & $129(17.8 \%)$ & \\
\hline Between 4th and 5th quantile & $37(15.5 \%)$ & $89(12.3 \%)$ & \\
\hline Educational level & & & 0.01 \\
\hline Primary/lower secondary & $42(17.6 \%)$ & $189(26.1 \%)$ & \\
\hline Upper secondary/post-secondary (non-tertiary) & $152(63.6 \%)$ & $389(53.7 \%)$ & \\
\hline Tertiary education (bachlor, master, doctoral) & 45 (18.8\%) & 146 (20.2\%) & \\
\hline
\end{tabular}

Note. Because of rounding not all percentages add up to $100 \%$. ${ }^{*} p$-value from chi-square test

correlation matrix of the 24 items is provided in Additional file 1 . The dataset had no values missing.

Given that the items were not normally distributed as becomes evident from the skewness and kurtosis values (Table 2) as well as the respective tests for univariate and multivariate normality $(p<0.001)$, robust maximum likelihood (MLR) confirmatory factor analysis (CFA) was used to examine the factorial validity of the WHOQOLBREF [36]. The standard measurement baseline model tested by means of CFA comprised the physical health (7 items), the psychological health (6 items), the social relationships (3 items) and the environment (8 items) factor [6]. In addition, the second-order factor measurement model, in which the four domains are conceptualized to be influenced by a higher-order dimension ('global quality of life') [6], was tested, considering that this measurement model is also frequently applied in substantive research. Differential item functioning related to gender was analyzed by means of multiple indicators multiple causes (MIMIC) models following established guidelines [36].

The fit of the measurement model was examined by means of the Tucker-Lewis index (TLI), the comparative fit index (CFI) and the standardized root mean square residual (SRMR) with TLI and CFI values $>0.90$ and SRMR values $\leq 0.08$ considered to indicate acceptable model fit. In addition, the root mean square error of approximation (RMSEA) was calculated with values $\leq 0.06$ considered indicating a good model fit $[37,38]$. To identify potential for model improvement, modification indices were calculated. Only theoretically sound modifications were implemented [36].

The reliability was assessed by means of composite reliability estimates based on the factor loadings estimated by the CFA model. Estimates $\geq 0.70$ were considered to indicate acceptable reliability in the latent dimensions [39]. In addition, Cronbach's alpha estimates were calculated. Given its limitations [36, 40], however, these estimates should only be interpreted with caution and are presented in this study mainly to facilitate comparisons with previous research that relied on that measure.

The analyses were performed by means of Stata 15 [41] and the R package lavaan 0.6-3 [42].

\section{Results}

Information on 239 men and 724 women with a chronic headache was available. Both groups did not differ from each other in terms of age, the proportion of individuals living with a partner and net equivalence income. Women had a slightly lower educational level, with a higher proportion of women having only a primary or lower secondary education (Table 1). 
Table 2 Descriptive statistics of the 24 items of the WHOQOL-BREF measurement model (individuals with self-reported chronic headache residing in Austria, Austrian Health Interview Survey, 2013-2015, $n=963$ )

\begin{tabular}{|c|c|c|c|c|c|c|}
\hline $\begin{array}{l}\text { Item } \\
\text { number }\end{array}$ & Item content & Mean & sd & Skewness & Kurtosis & $\begin{array}{l}p- \\
\text { value }^{\mathbf{b}}\end{array}$ \\
\hline 3. & $\begin{array}{l}\text { To what extent do you feel that physical pain prevents you from doing what you need to } \\
\text { do? }\end{array}$ & 2.36 & 1.20 & 0.52 & 2.24 & $<0.001$ \\
\hline 4. & How much do you need any medical treatment to function in your daily life? ${ }^{1}$ & 2.07 & 1.26 & 0.90 & 2.55 & $<0.001$ \\
\hline 5. & How much do you enjoy life? & 3.60 & 0.88 & -0.40 & 2.99 & $<0.001$ \\
\hline 6. & To what extent do you feel your life to be meaningful? ${ }^{1}$ & 4.03 & 0.96 & -0.96 & 3.59 & $<0.001$ \\
\hline 7. & How well are you able to concentrate? ${ }^{2}$ & 3.72 & 0.84 & -0.51 & 3.29 & $<0.001$ \\
\hline 8. & How safe do you feel in your daily life? ${ }^{2}$ & 3.90 & 0.80 & -0.68 & 3.90 & $<0.001$ \\
\hline 9. & How healthy is your physical environment? ${ }^{2}$ & 3.93 & 0.83 & -0.69 & 3.92 & $<0.001$ \\
\hline 10. & Do you have enough energy for everyday life? ${ }^{3}$ & 3.61 & 0.89 & -0.32 & 2.80 & $<0.001$ \\
\hline 11. & Are you able to accept your bodily appearance? ${ }^{3}$ & 3.89 & 0.92 & -0.69 & 3.41 & $<0.001$ \\
\hline 12. & Have you enough money to meet your needs? & 3.31 & 1.11 & -0.24 & 2.40 & $<0.001$ \\
\hline 13. & How available to you is the information that you need in your day-to-day life? ${ }^{3}$ & 4.19 & 0.86 & -0.93 & 3.44 & $<0.001$ \\
\hline 14. & To what extent do you have the opportunity for leisure activities? ${ }^{3}$ & 3.66 & 1.07 & -0.38 & 2.35 & $<0.001$ \\
\hline 15. & How well are you able to get around? ${ }^{4}$ & 4.19 & 0.90 & -0.98 & 3.46 & $<0.001$ \\
\hline 16. & How satisfied are you with your sleep? ${ }^{5}$ & 3.44 & 1.18 & -0.50 & 2.32 & $<0.001$ \\
\hline 17. & How satisfied are you with your ability to perform your daily living activities? ${ }^{5}$ & 3.84 & 0.98 & -0.85 & 3.31 & $<0.001$ \\
\hline 18. & How satisfied are you with your capacity for work $?^{5}$ & 3.74 & 1.13 & -0.91 & 3.07 & $<0.001$ \\
\hline 19. & How satisfied are you with yourself? $?^{5}$ & 3.86 & 0.95 & -0.86 & 3.45 & $<0.001$ \\
\hline 20. & How satisfied are you with your personal relationships? ${ }^{5}$ & 4.09 & 0.96 & -1.14 & 4.12 & $<0.001$ \\
\hline 21. & How satisfied are you with your sex life? ${ }^{5}$ & 3.56 & 1.09 & -0.71 & 2.98 & $<0.001$ \\
\hline 22. & How satisfied are you with the support you get from your friends? & 3.90 & 0.93 & -1.03 & 4.27 & $<0.001$ \\
\hline 23. & How satisfied are you with the conditions of your living place? ${ }^{5}$ & 4.18 & 0.93 & -1.23 & 4.31 & $<0.001$ \\
\hline 24. & How satisfied are you with your access to health services? ${ }^{5}$ & 3.98 & 0.89 & -1.06 & 4.38 & $<0.001$ \\
\hline 25. & How satisfied are you with your transport? $?^{5}$ & 3.87 & 0.99 & -0.93 & 3.66 & $<0.001$ \\
\hline 26. & $\begin{array}{l}\text { How often do you have negative feelings such as blue mood, despair, anxiety, } \\
\text { depression? }\end{array}$ & 2.63 & 1.00 & 0.32 & 2.55 & $<0.001$ \\
\hline
\end{tabular}

Note. ${ }^{\text {T}}$ The numbering is in accordance with the item sequence of the WHOQOL-BREF, of which only items 3 to 26 are part of the measurement model (see Methods section). ${ }^{\text {b }}$-value from D'Agostino and Pearson's chi-square omnibus test for normality. Response format: "Not at all" to "An extreme amount"; ${ }^{2 "}$ Not at all" to "Extremely"; ${ }^{3 " N o t}$ at all" to "Completely"; ${ }^{4 \prime}$ Very poor" to "Very good"; ${ }^{5 \prime}$ Very dissatisfied" to "Very satisfied"; $6 "$ Never" to "always"

The four-factor, 24-item baseline model showed a moderate fit $\left(\chi^{2}=1290.309\right.$, degrees of freedom $[\mathrm{df}]=246$, $p<0.001 ; \quad$ RMSEA $=0.066 ; \quad$ CFI $=0.868 ; \quad$ TLI $=0.852$; SRMR $=0.053$. After the addition of six error covariances between items 3 and 4 and 17 and 18 of the physical health factor, items 11 and 19 of the psychological health factor, items 19 and 20 of the psychological health and social relationships factor, respectively, and items 12 and 13 and 24 and 25 of the environment factor (Fig. 1) the model fit improved significantly $\left(\mathrm{X}^{2}=873.394, \mathrm{df}=\right.$ 240; $p<0.001$; RMSEA $=0.052 ; \mathrm{CFI}=0.920$; $\mathrm{TLI}=0.908$; SRMR $=0.046$ ). Two items of the environment factor ( 9 and 25) had low completely standardized factor loadings $(\lambda)$ of 0.49 and 0.40 respectively; all other factor loadings were of acceptable size $(\lambda \geq 0.5)$. All factor loadings were significant at $p<0.001$. The fit of the second-order measurement model did not differ from the first-order model $\left(\chi^{2}=879.429, \mathrm{df}=242, \mathrm{p}<0.001\right.$; RMSEA $=0.052$; $\mathrm{CFI}=0.919 ;$ TLI $=0.908 ; \mathrm{SRMR}=0.046$ ).

Composite reliability estimates for the WHOQOLBREF physical, psychological, social relationships and environment factor were $0.87,0.84,0.67$ and 0.77 , respectively. The respective Cronbach's alpha values were $0.83,0.80,0.64$ and 0.77 , respectively.

Differential item functioning related to sex was observed in items 9 and 14 of the environment factor, items 11 and 26 of the psychological health factor and items 15 and 18 of the physical health factor as evidenced by significant direct effects of sex on these items while holding the respective factors constant. The effects $(\beta=-0.068, \beta=-0.054, \beta=-0.108, \beta=0.096, \beta=0.076$ and $\beta=0.084$, respectively), however, were small in size and did not bias the comparison between men and women. Irrespective of adjusting for DIF related to sex, 


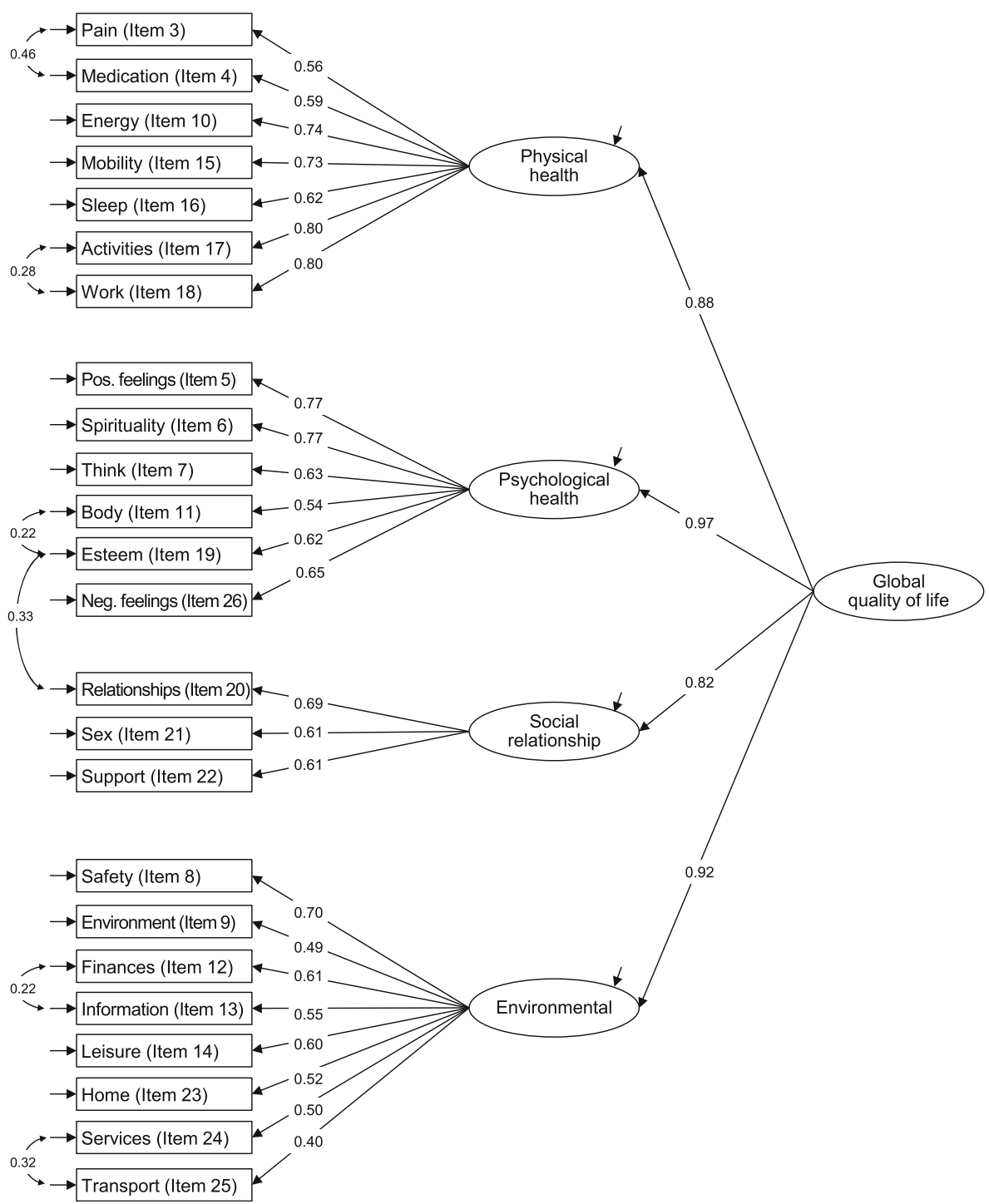

Fig. 1 Factor structure of the WHOQOL-BREF in individuals with self-reported chronic headache residing in Austria (numbers displayed on the straight and curved arrows signify completely standardized factor loadings and covariances, respectively; Austrian Health Interview Survey, 20132015, $n=963$; All factor loadings/covariances were significant at $p<0.001$ )

no significant difference in quality of life was identified between men and women.

\section{Discussion}

The WHOQOL-BREF is a frequently used instrument for the assessment of HRQOL. Although applied for the assessment of HRQOL among individuals with headache disorders [16-19], little is known about its psychometric properties. The present study examined the reliability and factor structure of the questionnaire in individuals with chronic headache in Austria and its equivalence between men and women.

The analysis showed that the physical health, psychological health and environment factor of the WHOQOL-
BREF had a satisfactory internal consistency. The internal consistency of the social relationships factor was below the recommended threshold of Cronbach's alpha $\geq 0.7$. Although meta-analytical results are inconsistant [43], evidence suggests that Cronbach's alpha tends to be smaller for factors with fewer items. Given that the social relationships factor consists only of three items, this could explain its low internal consistency as compared to the other factors identified in this study as well as previous research $[44,45]$. The respective composite reliability estimate was slightly larger, however still below the threshold of 0.7. This may indicate some general limitation of the social relationships dimension, which also previous studies had pointed to [13, 46-49]. 
The present analysis further revealed that the standard WHOQOL-BREF measurement model only showed a moderate fit among individuals with chronic headache in Austria. The fit improved significantly in a reparameterized model after the addition of six error covariances. Five of these covariances concerned items of the same factor, while one error covariance was between items belonging to different factors each (item 19: "How satisfied are you with yourself?" and item 20: "How satisfied are you with your personal relationships?"). It can be assumed that the latter error covariance results from the items being presented subsequently and their conceptual similarity. Also previous research conducted on the factor structure of the WHOQOL-BREF in other population groups suggested that adding error covariances is necessary to improve model fit $[22,50]$. Although the addition of these error covariances followed theoretical considerations and the error covariances added were similar to those in previous research, these post hoc modifications applied to the model have to be considered an exploratory type of examination and should, therefore, be cross-validated in other populations.

With the aforementioned modifications implemented, the WHOQOL-BREF can be considered a valid instrument for the assessment of HRQOL in individuals with chronic headache. However, as the analysis has shown, some items are prone to DIF related to sex. This corresponds to findings from research that has been conducted in other settings $[44,51]$. Although in the present study DIF was small in size, this potential bias, in general, needs to be taken into account to ensure valid estimates when comparing HRQOL between males and females. Latent variable modeling provides a valuable approach for this purpose and also allows to take into account the aforementioned modifications in terms added error covariances [36].

To the best of the author's knowledge, this is the first study which examines the psychometric properties of the WHOQOL-BREF in a population with headache disorders. Strength of the present study are its large and nationwide sample as well as the high quality of the data collection [32]. Limitations particularly concern its narrow focus on the population in Austria and chronic headache in general. Future studies should further examine whether the results of the present investigation are also applicable to the study of the HRQOL of individuals with different subtypes of headache and of those who live in other language regions [52]. Furthermore, also other domains of validity of the WHOQOL-BREF in individuals with headache disorders, such as content, convergent and divergent validity need to be explored. Finally, the sources of model ill-fit identified in this study as well as in previous investigations could indicate some general problems of the WHOQOL-BREF measurement model, which should be further investigated in future research, both on headache disorders as well as on other conditions.

\section{Conclusion}

The WHOQOL-BREF is frequently used for the assessment of HRQOL among individuals with chronic conditions. The present study shows that after some modifications the WHOQOL-BREF can also be considered valid for the assessment of HRQOL among individuals with chronic headache. Because of these modifications and the questionnaire's susceptibility for differential item functioning, a latent variable framework should be employed for the analysis.

\section{Supplementary information}

Supplementary information accompanies this paper at https://doi.org/10 1186/s12883-020-01845-7.

Additional file 1 Correlations between the 24 WHOQOL-BREF items (individuals with self-reported chronic headache residing in Austria, Austrian Health Interview Survey, 2013-2015, $n=963$ )

\section{Abbreviations \\ DIF: Differential item functioning; CFA: Confirmatory factor analysis; CFI: Comparative fit index; df: Degrees of freedom; EQ-5D: European quality of life index version 5D; HRQOL: Health-related quality of life; ISCED: International Standard Classification of Education; MIMIC: Multiple indicators multiple causes; MLR: Robust maximum likelihood; RMSEA: Root Mean Square Error of Approximation; TLI: Tucker-Lewis-Index; SF-36: Short Form (36) Health Survey; SRMR: Standardized root mean square residual; WHOQOL: World Health Organization Quality of Life questionnaire; WHOQOL-BREF: World Health Organization Quality of Life questionnaire (short version)}

\section{Acknowledgements}

Not applicable. The abstract was presented at the 26th Annual Conference of the International Society for Quality of Life Research [31].

\section{Author's contributions}

PB was responsible for the conception of the study as well as the secondary data analysis and interpretation as well as for writing the manuscript.

\section{Funding}

None.

\section{Availability of data and materials}

Data used in the present study is available for researchers as a Scientific Usefile free of charge from Statistics Austria upon request [32]; see the following website for details (only available in German language): https:// www.sozialministerium.at/Themen/Gesundheit/Gesundheitssystem/ Gesundheitsberichte/ (from here click on "Österreichische Gesundheitsbefragung 2014").

\section{Ethics approval and consent to participate}

Participation in the anonymous survey was voluntary and survey participants provided informed consent prior to their participation. Given national guidelines and recommendations for secondary data analyses, no further ethical approval was necessary to conduct the present analysis [53].

Consent for publication

Not applicable.

Competing interests

The author declares that he has no competing interests. 
Received: 29 May 2019 Accepted: 26 June 2020

Published online: 03 July 2020

\section{References}

1. Fayers P, Machin D. Quality of life: the assessment, analysis and interpretation of patient-reported outcomes. West Sussex: Wiley; 2013.

2. Lipton RB, Rosen NL, Ailani J, et al. OnabotulinumtoxinA improves quality of life and reduces impact of chronic migraine over one year of treatment: pooled results from the PREEMPT randomized clinical trial program. Cephalalgia. 2016;36:899-908.

3. Sullivan A, Cousins S, Ridsdale L. Psychological interventions for migraine: a systematic review. J Neurol. 2016;263:2369-77.

4. Rollnik JD, Karst M, Piepenbrock S, et al. Gender differences in coping with tension-type headaches. Eur Neurol. 2003;50:73-7.

5. Walters SJ. Quality of life outcomes in clinical trials and health-care evaluation: a practical guide to analysis and interpretation. 84 ed. John Wiley \& Sons; 2009.

6. The WHOQOL Group. Development of the World Health Organization WHOQOL-BREF quality of life assessment. Psychol Med. 1998;28:551-8.

7. The WHOQOL Group. The World Health Organization quality of life assessment (WHOQOL): development and general psychometric properties. Soc Sci Med. 1998;46:1569-85.

8. Engin B, Uguz F, Yilmaz E, et al. The levels of depression, anxiety and quality of life in patients with chronic idiopathic urticaria. J Eur Acad Dermatol Venereol. 2008;22:36-40.

9. Liang WM, Chen JJ, Chang $\mathrm{CH}$, et al. An empirical comparison of the WHOQOL-BREF and the SGRQ among patients with COPD. Qual Life Res. 2008;17:793-800.

10. Souza CA, Oliveira LM, Scheffel C, et al. Quality of life associated to chronic pelvic pain is independent of endometriosis diagnosis-a cross-sectional survey. Health Qual Life Outcomes. 2011;9:41.

11. Rusli BN, Edimansyah BA, Naing L. Working conditions, self-perceived stress, anxiety, depression and quality of life: a structural equation modelling approach. BMC Public Health. 2008;8:48.

12. Van de Willige G, Wiersma D, Nienhuis FJ, et al. Changes in quality of life in chronic psychiatric patients: a comparison between EuroQol (EQ-5D) and WHOQoL. Qual Life Res. 2005;14:441-51.

13. Asnani MR, Lipps GE, Reid ME. Utility of WHOQOL-BREF in measuring quality of life in sickle cell disease. Health Qual Life Outcomes. 2009:7:75.

14. Chachamovich JL, Chachamovich E, Ezer H, et al. Psychological distress as predictor of quality of life in men experiencing infertility: a cross-sectional survey. Reprod Health. 2010;7:3.

15. ZamZam R, Midin M, Hooi LS, et al. Schizophrenia in Malaysian families: a study on factors associated with quality of life of primary family caregivers. Int J Ment Heal Syst. 2011;5:16.

16. Song MK, Choi SH, Lee DH, et al. Effects of cognitive-behavioral therapy on empathy in patients with chronic pain. Psychiatry Investig. 2018;15:285.

17. Lim JA, Choi SH, Lee WJ, et al. Cognitive-behavioral therapy for patients with chronic pain: implications of gender differences in empathy. Medicine (Baltimore). 2018:97.

18. Rashid-Tavalai Z, Bakhshani NM, Amirifard H, et al. Effectiveness of combined copying skills training and pharmacological therapy for patients with migraine. Global J Health Sci. 2016;8:179.

19. de Andrade Vieira RV, Vieira DC, Gomes WB, et al. Alexithymia and its impact on quality of life in a group of Brazilian women with migraine without aura. J Headache Pain. 2013:14:18.

20. Yao G, Wu C. Factorial invariance of the WHOQOL-BREF among disease groups. Qual Life Res. 2005;14:1881-8.

21. Hwang HF, Liang WM, Chiu YN, et al. Suitability of the WHOQOL-BREF for community-dwelling older people in Taiwan. Age Ageing. 2003;32:593-600.

22. Suarez L, Tay B, Abdullah F. Psychometric properties of the World Health Organization WHOQOL-BREF quality of life assessment in Singapore. Qual Life Res. 2018;27:2945-52.

23. Trompenaars FJ, Masthoff ED, Van Heck GL, et al. Content validity, construct validity, and reliability of the WHOQOL-Bref in a population of Dutch adult psychiatric outpatients. Qual Life Res. 2005;14:151-60.

24. Chang KC, Wang JD, Tang HP, et al. Psychometric evaluation, using Rasch analysis, of the WHOQOL-BREF in heroin-dependent people undergoing methadone maintenance treatment: further item validation. Health Qual Life Outcomes. 2014;12:148.
25. Rocha NSd, Fleck MPdA. Validity of the Brazilian version of WHOQOL-BREF in depressed patients using Rasch modelling. Rev Saude Publica 2009;43: 147-153.

26. Wang WC, Yao G, Tsai YJ, et al. Validating, improving reliability, and estimating correlation of the four subscales in the WHOQOL-BREF using multidimensional Rasch analysis. Qual Life Res. 2006;15:607-20.

27. Scott NW, Fayers PM, Aaronson NK, et al. The practical impact of differential item functioning analyses in a health-related quality of life instrument. Qual Life Res. 2009;18:1125-30.

28. Haywood KL, Mars TS, Potter R, et al. Assessing the impact of headaches and the outcomes of treatment: a systematic review of patient-reported outcome measures (PROMs). Cephalalgia. 2018;38:1374-86.

29. Pellesi L, Benemei S, Favoni V, et al. Quality indicators in headache care: an implementation study in six Italian specialist-care centres. J Headache Pain. 2017;18:55.

30. Peters M, Perera S, Loder E, et al. Quality in the provision of headache care. 1: systematic review of the literature and commentary. J Headache Pain 2012;13:437

31. Brzoska P. Assessment of quality of life in individuals with chronic headache Presentation at the 26th Annual Conference of the International Society for Quality of Life Research, Oct. 20-23, 2019. 2019 (https://link.springer.com/ article/10.1007/s11136-019-02257-y; https://www.eventscribe.com/2020/ ISPRM/fsPopup.asp? PosterID=259366\&efp=RUpFWIBSWEI5NTY0\&mode= posterinfo\&rnd=6.180048E-02)

32. Statistik Austria. Standard-Dokumentation. Metainformationen (Definitionen, Erläuterungen, Methoden, Qualität) zur Österreichische Gesundheitsbefragung 2014. Statistik Austria: Wien; 2016.

33. UNESCO Institute for Statistics. International standard classification of education: ISCED 2011. UNESCO Institute for Statistics Montreal; 2012.

34. D'Agostino R, Pearson ES. Tests for departure from normality. Biometrika. 1973;60:613-22.

35. Henze N, Zirkler B. A class of invariant consistent tests for multivariate normality. Commun Stat Theor Methods. 1990;19:3595-617.

36. Brown T. Confirmatory factor analysis for applied research. New York: Guilford; 2015

37. Bentler PM. Comparative fit indexes in structural models. Psychol Bull. 1990; 107:238-46.

38. Hu L, Bentler PM. Cutoff criteria for fit indexes for in covariance structure analysis: conventional criteria versus new alternatives. Struct Equ Model. 1999;6:1-55.

39. Nunnally J, Bernstein IH. Psychometric theory. New York: McGraw-Hill; 1994.

40. Raykov T. Bias of coefficient afor fixed congeneric measures with correlated errors. Appl Psychol Meas. 2001;25:69-76.

41. StataCorp. Stata Statistical Software: Release 15. College Station: StataCorp LP: 2017.

42. Rosseel Y, Oberski D, Byrnes J, et al. Package 'lavaan'. R package version 0.63. 2018

43. Peterson RA. A meta-analysis of Cronbach's coefficient alpha. J Consum Res. 1994:21:381-91.

44. Krägeloh CU, Kersten P, Billington DR, et al. Validation of the WHOQOL-BREF quality of life questionnaire for general use in New Zealand: confirmatory factor analysis and Rasch analysis. Qual Life Res. 2013;22:1451-7.

45. Kalfoss MH, Low G, Molzahn AE. The suitability of the WHOQOL-BREF for Canadian and Norwegian older adults. Eur J Ageing. 2008;5:77.

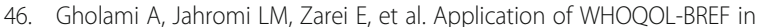
measuring quality of life in health-care staff. Int J Prev Med. 2013;4:809.

47. Jang $Y$, Hsieh $C L$, Wang $Y H$, et al. A validity study of the WHOQOL-BREF assessment in persons with traumatic spinal cord injury. Arch Phys Med Rehabil. 2004;85:1890-5.

48. Xia P, Li N, Hau KT, et al. Quality of life of Chinese urban community residents: a psychometric study of the mainland Chinese version of the WHOOOL-BREF. BMC Med Res Methodol. 2012:12:37.

49. Nedjat S, Montazeri A, Holakouie K, et al. Psychometric properties of the Iranian interview-administered version of the World Health Organization's quality of life questionnaire (WHOQOL-BREF): a population-based study. BMC Health Serv Res. 2008:8:61.

50. de Mol M, Visser S, Aerts JG, et al. Satisfactory results of a psychometric analysis and calculation of minimal clinically important differences of the World Health Organization quality of life-BREF questionnaire in an observational cohort study with lung cancer and mesothelioma patients. BMC Cancer. 2018;18:1173. 
51. Liang WM, Chang $\mathrm{CH}$, Yeh $\mathrm{YC}$, et al. Psychometric evaluation of the WHOQOL-BREF in community-dwelling older people in Taiwan using Rasch analysis. Qual Life Res. 2009;18:605-18.

52. Abu Bakar N, Tanprawate S, Lambru G, et al. Quality of life in primary headache disorders: a review. Cephalalgia. 2016;36:67-91.

53. Arbeitsgruppen 'Erhebung und Nutzung von Sekundärdaten' und 'Epidemiologische Methoden' der DGSMP/DGEpi/GMDS. GPS - Gute Praxis Sekundärdatenanalyse: Revision nach grundlegender Überarbeitung. Gesundheitswesen. 2008;70:54-60.

\section{Publisher's Note}

Springer Nature remains neutral with regard to jurisdictional claims in published maps and institutional affiliations.

Ready to submit your research? Choose BMC and benefit from:

- fast, convenient online submission

- thorough peer review by experienced researchers in your field

- rapid publication on acceptance

- support for research data, including large and complex data types

- gold Open Access which fosters wider collaboration and increased citations

- maximum visibility for your research: over $100 \mathrm{M}$ website views per year

At $\mathrm{BMC}$, research is always in progress.

Learn more biomedcentral.com/submissions 